the possibility that such deficits persist on long-term use. Further studies are urgently needed, which we hope we will be able to undertake.

H Petursson M H LADER

Institute of Psychiatry,

London SE5 8AF

1 Petursson H, Lader MH. Br Med F 1981;283:643-5. 2 Wittenborn JR. Br f Clin Pharmacol 1979;7:6is. Johnson LC, Chernik DA. Psychopharmacology 1982; 76:101.

\section{Healthier children}

SIR,-Healthier Children: Thinking Prevention, the report of a working party appointed by the Council of the Royal College of General Practitioners (17 July, p 224) seems likely to attract much interest and discussion. Among the wide-ranging recommendations and conclusions reached, the report contains several different developmental surveillance schedules. Without intending to trivialise this important report at this early stage, I nevertheless feel some concern that the development screen given prominence in the text (adapted from Eggertsen, Schneeweiss, and Bergman) uses "matches in box" for $4 \frac{1}{2}$-year-olds. I am reminded of a report in the Pharmaceutical fournal ${ }^{1}$ of an inquest on an 18-month-old boy who died after accidentally taking a drug overdose, whose mother claimed her son had been shown how to get a sweet out of a tablet bottle by a health visitor using the Denver developmental screening test.

C R HAINES

Peterborough Health Authority School Health Service,

1 Anonymous. Pharmaceutical fournal 1982;228:April $10: 422$.

\section{Claims about compression treatment for venous disease}

SIR,-In the recent correspondence on compression in venous disease $\mathrm{Mr} \mathrm{A} \mathrm{B} \mathrm{D}$ Chant (7 August, p 439) refers to the use of hydrostatic compression. Several years ago A J M Brodribb and I carried out some preliminary experiments on hydrostatic compression applied to venous problems in the leg. The results were certainly encouraging and indicated that this principle deserved more intensive investigation. It allows appropriate pressure to be exerted in a graduated fashion, immediately adjusting to the position of the limb, and can be applied continuously or as an intermittent pressure powered by body weight. It is perhaps not sufficiently known that $\mathrm{Dr} \mathrm{V}$ Holan of Czechoslovakia has gone a long way towards the successful development of a practical hydrostatic device consisting of a shaped rubber bag which is applied to the inner aspect of the leg with a bandage and extended to the underside of the foot so that pressure is transferred intermittently to the ankle region with each step. ${ }^{1}$ Dr Holan has reported good results over some years and his methods warrant thorough evaluation in Britain. He has kindly sent me a specimen of his hydrostatic support which I am very willing to show to any surgeon or manufacturer who is interested (Holan hydrostatic bag).

Surgery has no reliable method of reconstructing the damaged or defective musculo- venous pump but in this technological age it should surely be possible to devise methods of intermittent external pressure to provide a substitute pumping action promoting venous return when the patient is upright. Sustained elastic compression does not fulfil this role satisfactorily, and hydrostatic pumping techniques should be explored.

\section{John Radcliffe Hospital,}

David J TiBbs

John Radcliffe Ho
Oxford OX3 9DU 'Holan V, Jiraskova M, Pankova R. Vasa 1976;5:
355-9.

\section{Paediatric surveillance}

SIR,-The failure of the GMSC's negotiations to persuade the Review Body to price routine developmental examinations as an item of service has allowed welcome time for further discussion on this topic. There appears to be confusion over what actually constitutes an examination, and reported claims that it is easy to carry out 15 to 20 such examinations in a two and a quarter hour session make us wonder what sort of examination our negotiators had in mind. Our experience over many years and many thousands of routine examinations is that no more than 8-10 are really possible in a session of two and a quarter hours.

More important is that there appears to be a misunderstanding about what part a regular "physical" plays in surveillance examination. We believe that it forms only one part of child surveillance in general practice. Surveillance entails accurate identification of all the under -5 population in any practice. Once this has been done, immunisation; nutritional guidance, including accurate regular weighing; health education; developmental guidance; and social support together with regular, meticulously carried out developmental examinations are all tasks that the general practice team of health visitors, midwife, nurse, and general practitioner should carry out as paediatric surveillance. Unless such a package of care is offered, which demands at the outset the closest interprofessional cooperation between the members of the team, paying for only one part of the package and hoping that everything else will happen is, we believe, overoptimistic.

In our opinion it is the non-functioning paediatric primary care team that is the greatest obstacle to progress; lack of commitment and lack of leadership are two reasons why the team does not function in many practices. Sadly, however, a lack of understanding about what preventive paediatric care can offer in general practice seems to be the main one. Child surveillance is time consuming and requires training and organisation, and the whole of the primary care team should be involved. Remuneration should reflect not just the doctor's time spent on offering services that attract an item of service payment but should be for accepting the responsibility for organisation and delivery of paediatric surveillance. For only when the true content of surveillance is appreciated and its effects felt and appropriately rewarded will the children of this country get the health care they deserve and, indeed, require.

P D HOOPER G H CURTIS JENKINS Ashford, Middlesex TW15 2TU

\section{GMC finance}

SIR,-Dr G W H Jardine writing on GMC finance (7 August, $\mathrm{p}$ 442) has misinterpreted the figures given in the Council's annual report. The cost of registration of overseasqualified doctors, $\$ 324545$, was more than covered by the corresponding income$£ 113390$ for registration plus $£ 43885$ for scrutiny fees and $£ 206350$ for fees for limited registration, making a total of $£ 363625$. Some contribution to the general expenditure of the Council was therefore derived both from the fees paid by British and Irish doctors and by overseas-qualified doctors.

The expenditure on the registration of EEC doctors and associated activities of $£ 33900$ was not covered by the fees of $£ 13040$ received for the full registration of EEC doctors, because to comply with the requirements of our membership of the EEC the fee charged for the registration of an incoming EEC doctor must be the same as that charged to a British-qualified doctor. The Council is thus not free to vary the fees to match the higher cost of registering an EEC doctor.

M R DRAPER

General Medical Council,

London W1N 6AE

Medical communication: the old and the new

SIR,-As a devout optimist, I would like to share Dr C C Booth's hope (10 July, p 105) that the present publishing climate may encourage Britain's healthy tradition of radical medical journalism. The portents, however, are not encouraging.

Just two pages beyond Dr Booth's article, Jerry Cowhig, editor of a first-rate newspaper for GPs, writes: "In editorial policy one must always aim for maximum readership." Because what advertisers measure is, at best, claimed readership there is a danger, as Jerry Cowhig admits, that an editor will play it safe by pandering to the readers' prejudices or massaging their egos.

Even more depressing were two items in the job specification issued by the "head hunters" commissioned to search for a new editor for World Medicine. The first reads: "As editor he will be expected to continuously look [sic] for new areas of interest for the readers and work closely with the advertisement manager to exploit possible revenue earning opportunities afforded by such new editorial content." The second item explains that a troika of managing director, advertisement manager, and editor "will be responsible for all aspects of the journal." Such a team, however well intentioned, seems unlikely to take the sort of risks that are central to the tradition that Dr Booth commends.

That tradition will, I submit, be resuscitated not by publishing techniques or methods of distribution but by individual publishers who tend to keep their "front office" free of those multinational accountants who flit from industry to industry measuring the worth of a rose by counting its petals and of an article by counting the words.

Michael O'DONNELI

Weybridge,
Surrey KT13 8SJ 